\title{
Síndrome de enterocolitis inducida por proteínas alimentarias por ingesta de kiwi como causa de evento potencialmente grave inexplicado en una niña Food Protein Induced Enterocolitis Syndrome due to ingestion of kiwi causing potentially severe unexplained event in a child
}

\author{
Dr. Francisco Álvarez Caro ${ }^{a}$, Lic. Sandra Rodríguez Fernández ${ }^{a}$ Lic. Elvira Barrio Traspaderne ${ }^{a}$ \\ Lic. Javier González García ${ }^{a}$ Lic. Begoña García Norniella ${ }^{a}$ y Lic. Ángela Gómez Farpón ${ }^{b}$
}

\begin{abstract}
RESUMEN
Elsíndrome de enterocolitisinducida por proteínas alimentarias es una alergia alimentaria no mediada por inmunoglobulina $\mathrm{E}$ que se manifiesta clínicamente con vómitos profusos y repetitivos, en ocasiones, asociados a diarrea, y puede llegar a asociar deshidratación y letargia, con riesgo de desarrollo de shock. A pesar de su potencial gravedad, el índice de sospecha de este síndrome es bajo, lo que demora su diagnóstico, especialmente, en aquellos casos que son desencadenados por alimentos sólidos. La presencia de vómitos y la duración de más de un minuto son los datos clave que pueden diferenciarlo de los episodios breves, resueltos e inexplicados. Se presenta el caso de una lactante de 6 meses de vida con diagnóstico final de síndrome de enterocolitis inducida por proteínas alimentarias por ingesta de kiwi.

Palabras clave: kiwi, sindrome de enterocolitis inducida por proteinas alimentarias, episodios breves, resueltos e inexplicados, vómitos, hipersensibilidad.
\end{abstract}

\begin{abstract}
Food protein-induced enterocolitis syndrome (FPIES) is a nonIgE food allergy manifesting as profuse, repetitive vomiting, sometimes with diarrhea, leading to dehydration and lethargy that can be severe and lead to shock. Despite the potential severity, awareness of FPIES is low and diagnosis is often delayed, especially in those triggered by solid foods. Presence of vomits and duration of more than 1 minute are the key differential factors to distinguish FPIES from brief resolved unexplained events. We report a case of a 6 -month-old infant finally diagnosed as having kiwi induced FPIES.

Key words: kiwi, food protein-induced enterocolitis syndrome, brief resolved unexplained events, vomiting, hypersensitivity.
\end{abstract}

http:/ / dx.doi.org/10.5546/ aap.2019.e178

a. Servicio de Pediatría, Hospital de Cabueñes, Gijón, España.

b. Área de Gestión de Pediatría, Hospital Universitario Central de Asturias, Oviedo, España.

Correspondencia:

Dr. Francisco Álvarez Caro: franciscoalvarez130@msn.com

Financiamiento: Ninguno.

Conflicto de intereses: Ninguno que declarar.

Recibido: 10-6-2018

Aceptado: 26-10-2018
Cómo citar: Álvarez Caro F, Rodríguez Fernández S, Barrio Traspaderne E, González García J, et al. Síndrome de enterocolitis inducida por proteínas alimentarias por ingesta de kiwi como causa de evento potencialmente grave inexplicado en una niña. Arch Argent Pediatr 2019;117(2):e178-e180.

\section{INTRODUCCIÓN}

El síndrome de enterocolitis inducida por proteínas alimentarias (Food Protein-Induced Enterocolitis Syndrome; FPIES, por sus siglas en inglés) es una alergia alimentaria no mediada por inmunoglobulina $\mathrm{E}$ ( $\mathrm{IgE}$ ) que se manifiesta clínicamente con vómitos profusos y repetitivos, en ocasiones, asociados a diarrea, que puede llegar a asociar deshidratación y letargia, con riesgo de desarrollo de shock. ${ }^{1,2}$ Los mecanismos subyacentes al FPIES son inciertos y pobremente caracterizados, por lo que se necesitan más estudios para un mejor conocimiento. El FPIES se puede clasificar en agudo y crónico. El agudo se caracteriza por la presencia de vómitos profusos repetidos, asociados a palidez y letargia, que acontecen entre 1 y 4 horas (habitualmente, 2) tras la ingesta del alimento desencadenante, mientras que el crónico se encuentra peor caracterizado y solo se ha descrito en lactantes menores de 4 meses alimentados con leche de fórmula de origen animal o de soja que desarrollan vómitos intermitentes, diarrea acuosa crónica y falla de medro durante un período de días-semanas. ${ }^{3}$ En ambos casos, la eliminación del alimento causal conlleva la resolución del cuadro clínico. ${ }^{3}$

\section{CASO CLÍNICO}

Se presenta el caso de una lactante de 6 meses de edad atendida en Urgencias de Pediatría por un episodio de alteración del nivel de conciencia, letargia, náuseas, vómitos repetidos, hipotonía y palidez. Este episodio no estaba relacionado con el llanto. No presentaba tortícolis, clonus, espasmos o revulsión ocular. La lactante estaba afebril y 
no tenía diarrea. Los padres no referían ningún desencadenante asociado. Existían antecedentes familiares de epilepsia, pero no presentaba antecedentes familiares ni personales de atopia. Al ingresar, la exploración física era normal. Permaneció hospitalizada durante 3 días sin presentar nuevos episodios similares al descrito al ingresar. Se realizó un electroencefalograma, que fue normal.

Tres días más tarde, fue evaluada por un nuevo episodio similar, que se desarrolló 2 horas después de la ingesta de papilla de frutas con kiwi en su composición. En ese momento, los padres relataron que, igualmente, el proceso previo había tenido lugar 2 horas después de la ingesta de kiwi, que había sido su primera exposición a este.

Se realizó prick test y determinación de $\operatorname{IgE}$ específica frente a kiwi: ambos fueron negativos (0 $\mathrm{mm}$ y $0 \mathrm{kU} / \mathrm{L}$, respectivamente).

Tras obtener el consentimiento informado, se realizó una prueba de exposición controlada con kiwi en régimen hospitalario, bajo supervisión médica y con las medicaciones, personal y equipos necesarios para tratar una eventual reacción. La prueba fue secuencial: se ingirieron 3 dosis iguales de kiwi cada hora hasta alcanzar 2 gramos de proteína (considerando que 100 gramos de kiwi contenían 1 gramo de proteínas). Dos horas tras la ingesta de la última dosis de kiwi, la paciente presentó un episodio de vómitos repetidos junto con palidez e hipotonía. Se realizó el diagnóstico de FPIES por ingesta de kiwi y se recomendó evitar su consumo.

\section{DISCUSIÓN}

El FPIES fue descrito y formalmente definido en la década de los setenta. ${ }^{2} \mathrm{Su}$ prevalencia real es desconocida y son escasos los datos acerca de los factores de riesgo, aunque son comunes los antecedentes familiares de atopia.

A pesar de la potencial gravedad de esta reacción, el índice de sospecha de FPIES es bajo y su diagnóstico se retrasa con frecuencia, en especial, cuando el alimento desencadenante es sólido, como en nuestro caso. ${ }^{4}$ Esta demora diagnóstica puede ser parcialmente explicada por el inicio no inmediato de los síntomas en relación con la ingesta del alimento, la falta de síntomas típicos de reacciones IgE mediadas (sibilancias o urticaria) o un bajo índice de sospecha de que algunos alimentos tuvieran un bajo potencial alergénico y no fueran considerados como causantes de reacciones alérgicas graves. En nuestro caso, el retraso diagnóstico se podría explicar por el hecho de que ni los padres ni el personal facultativo asociaron en primer lugar la ingesta de kiwi con el cuadro clínico experimentado por la paciente.

Aunque, teóricamente, cualquier alimento puede inducir este síndrome y existe una variación geográfica, la mayoría de los desencadenantes descritos son leche de vaca, soja y cereales. ${ }^{5-7}$ Aunque el kiwi ha sido reconocido durante años como alérgeno alimentario, se asocia, sobre todo, a reacciones IgE mediadas y se describe raramente como desencadenante de reacciones no IgE mediadas, como nuestro caso. De hecho, el kiwi como desencadenante del FPIES está descrito en menos del $0,5 \%$ de los pacientes. ${ }^{8}$

La historia natural del FPIES agudo es habitualmente benigna. Se considera una entidad autolimitada, y la mayoría se resuelve de forma espontánea a los 3-5 años de edad, si bien el desarrollo de tolerancia espontánea en pacientes con FPIES inducido por un alimento sólido es más tardío que en los desencadenados por leche de vaca o soja. ${ }^{3}$

El diagnóstico de FPIES se basa en la historia clínica, en la exclusión de otras etiologías y en una prueba de exposición controlada (esta última es la prueba definitiva). Muchos lactantes no precisan realizar la prueba de exposición controlada, en especial, si tienen una historia de reacciones graves, se encuentran asintomáticos tras la eliminación del alimento casual y presentan un desencadenante habitual. En nuestro caso, el kiwi raramente está descrito como agente causal de FPIES, por lo que se considera apropiada la realización de una prueba de exposición controlada que confirme el diagnóstico. De acuerdo con las últimas guías de consenso, nuestro paciente no solo cumplía los criterios de sospecha de FPIES agudo, sino también los criterios de interpretación de una prueba de exposición controlada en pacientes con sospecha de FPIES. ${ }^{9}$

El diagnóstico diferencial de FPIES es extenso e incluye otras reacciones alérgicas alimentarias, enfermedades infecciosas, metabólicas o neurológicas, entre otras. Se debe enfatizar que los episodios breves, resueltos e inexplicados (brief resolved unexplained event; $B R U E$, por sus siglas en inglés), previamente conocidos como episodios aparentemente letales (apparent life-threatening event; ALTE, por sus siglas en inglés) deben incluirse en el diagnóstico diferencial, dado que el término BRUE se define como un evento ocurrido en un lactante menor de 1 año de vida cuando el 
observador refiere un evento imprevisto, breve y resuelto de uno o más de los siguientes: 1 . cianosis o palidez, 2. ausencia, disminución o respiración irregular, 3. cambio marcado en el tono muscular (hipo- o hipertonía) y 4 . alteración en el nivel de respuesta. El BRUE se diagnostica solo cuando no existe una explicación para dicho evento tras una historia clínica y examen físico adecuado. ${ }^{10} \mathrm{De}$ acuerdo con esta definición, muchos pacientes con FPIES, especialmente aquellos casos inducidos por alimentos sólidos, podrían tener diagnóstico inicial de $B R U E$, pero es importante destacar que los síntomas de BRUE deben durar menos de un minuto. ${ }^{10}$ Las manifestaciones del FPIES varían de acuerdo con la frecuencia y la dosis del alimento ingerido, así que los eventos de breve duración (menos de 1 minuto) podrían ser posibles, pero, en la práctica, los episodios agudos de FPIES son de mayor duración. Otro dato relevante para diferenciar FPIES de BRUE son los vómitos, que son constantes en el primero y un factor de exclusión en el segundo. ${ }^{10}$

En conclusión, el FPIES es un diagnóstico importante para considerar no solo por alergólogos infantiles y pediatras, sino también por médicos de urgencias ante todo lactante que acude con vómitos repetidos, alteración del nivel de conciencia, letargia, hipotonía y palidez con o sin diarrea. Dado que muchos lactantes podrían tener diagnóstico inicial de BRUE, este tipo de pacientes debe ser monitorizado e interrogado de manera minuciosa, específicamente acerca de posibles desencadenantes alimentarios, con el objetivo de evitar pruebas y medidas innecesarias. La presencia de vómitos y la duración superior a un minuto son los datos clave para establecer el diagnóstico diferencial.

\section{REFERENCIAS}

1. BoyceJA, Assa'ad A, Burks AW, Jones SM, et al. Guidelines for the diagnosis and management of food allergy in the United States: summary of the NAID-sponsored Expert Panel Report. J Allergy Clin Immunol. 2010; 126(6):1105-18.

2. Powel GK. Milk and soy induced enterocolitis of infancy. Clinical features and standardization of challenge. J Pediatr. 1978; 93(4):553-60.

3. Nowak-Węgrzyn A, Jarocka-Cyrta E, Moschione Castro A. Food Protein-Induced Enterocolitis Syndrome. J Investig Allergol Clin Immunol. 2017; 27(1):1-18.

4. Caubet JC, Nowak-Wegrzyn A. Food protein-induced enterocolitis to hen's egg. J Allergy Clin Immunol. 2001; 128(6):1386-8.

5. Hwang JB, Sohn SM, Kim AS. Prospective follow-up oral food challenge in food protein-induced enterocolitis syndrome. Arch Dis Child. 2009; 94(6):425-8.

6. Katz Y, Goldberg MR, Rajuan N, Cohen A, et al. The prevalence and natural course of food protein-induced enterocolitis syndrome to cow's milk: a large-scale, prospective population-based study.J Allergy Clin Immunol. 2011; 127(3):647-53.

7. Nomura I, Morita H, Hosokawa S, Hoshina H, et al. Cluster analysis revealed four distinct subtypes of non-IgEmediated gastrointestinal food allergies in neonates and infants, distinguished by their initial symptoms. Allergy 2011; 66:395.

8. Ruffner MA, Ruymann K, Barni S, Cianferoni A, et al. Food protein-induced enterocolitis syndrome: insights from review of a large referral population. J Allergy Clin Immunol Pract. 2013; 1(4):343-9.

9. Nowak-Wegrzyn A, Chehade M, Groetch ME, Spergel JM, et al. International consensus guidelines for the diagnosis and management of food protein-induced enterocolitis syndrome: Executive summary-Workgroup Report of the Adverse Reactions to Foods Committee, American Academy of Allergy, Asthma \& Immunology. J Allergy Clin Immunol. 2017; 139(4):1111-26.

10. Tieder JS, Bonkowsky JL, Etzel RA, Franklin WH, et al. Brief Resolved Unexplained Events (Formerly Apparent Life-Threatening Events) and Evaluation of Lower-Risk Infants. Pediatrics. 2016; 137(5):e20160590. 